\title{
Applications of robot assisted language learning (RALL) in language learning and teaching
}

\author{
Nader Assadi Aidinlou' ${ }^{1}$, Minoo Alemi ${ }^{2}$, Fahime Farjami ${ }^{3}$, Muhammad Makhdoumi ${ }^{1}$ \\ ${ }^{1}$ Department of English Language Teaching, Ahar Branch, Islamic Azad University, Ahar, Iran \\ ${ }^{2}$ Post Doctoral Research Associate, Faculty of Applied Linguistics, Sharif University of Technology, Iran \\ ${ }^{3}$ Young Researchers and Elite Club, Ahar Branch, Islamic Azad University, Ahar, Iran
}

\section{Email address:}

naderasadi@yahoo.com (N. A. Aidinlou), alemi@sharif.ir (M. Alemi), fahimefarjami@yahoo.com (F. Farjami), mmakdoumi@gmail.com (M. Makhdoumi)

\section{To cite this article:}

Nader Assadi Aidinlou, Minoo Alemi, Fahime Farjami, Muhammad Makhdoumi. Applications of Robot Assisted Language Learning (RALL) in Language Learning and Teaching. International Journal of Language and Linguistics. Special Issue: Foreign Language Teaching and Learning (Models and Beliefs). Vol. 2, No. 3-1, 2014, pp. 12-20. doi: 10.11648/j.ijll.s.2014020301.12

\begin{abstract}
This study covers a complete overview of the theoretical rationale of application of robots, other instructional inter faces like CALL, MALL, m-learning, r-learning, different types of robots, their instructional roles, their educational activities, the related researches, findings, and challenges of robotic assisted language learning . Since robotic revolution, many investigators in different countries have attempted to utilize robots to enhance education. As many people in the world have personal computers (PCs), in the following years, Personal Robots (PR) may become the next tool for every one's life. Robots not only have the attributes of CALL/MALL, but also are able for independent movements, voice/visual recognition and environmental interactions, non-verbal communication, collaboration with native speakers, diagnosing pronunciation, video conferencing with native speakers, native speaker tutoring, adaptability, sensing, repeatability, intelligence, mobility and human appearance. Robot- aided learning ( $\mathrm{r}$ - learning) services can be described as interactive and instructional activities which can be interacted and performed between robots and learners in both virtual and real worlds.
\end{abstract}

Keywords: RALL, CALL, MALL

\section{Introduction}

Since robotic revolution, robots have been designed and developed for different objectives and requirements. Notwithstanding, with the technology enhancement, it was predicted that in near future, robots will be used in second and foreign language teaching and learning and as the result will get more appreciation as a useful tool for first, second and foreign language teaching. This study will cover a complete overview of the theoretical rationale of application of robots, other instructional inter faces like CALL, MALL, m-learning, r-learning, different types of robots, their instructional roles, their educational activities, the related researches and their findings, challenges of robotic assisted language learning and finally the gap of the literature will be stated.

\section{The Review of Literature}

Utilizing robots to enhance teaching and learning, from kindergarten to undergraduate education, has become a widely popular research field in modern world (Ryu, Kwak \& Kim, 2000).Many investigators have attempted to utilize robots to support and enhance education. The previous studies have indicated that robots can help students learn computer program, science, mathematics, and problem solving. The first person who used an educational robot and can be considered the father of this field is Seymour Papert. He suggested "constructionism" as an approach to learn in classroom, which was opposed to "instructionism". By this approach, pupils are able to learn from designing and assembling their own robotic systems. As many younger learners are fascinated by robots, they have been valid as useful educational devices for instructing physics and mathematics. 
Because of rapid growth of communication technology, material developers and educators attempt to understand and keep up with astonishing changes in our electronic world. Novel applications of educational robots in the form of Socially Assistive Robots (SAR) have been found and discovered as teaching assistants. As many people in the world have personal computer (PC) in the following years, Personal Robots (PR) may become the next tool for every ones' life. So studies need to be done on how robots will cause changes in instruction. It is very interesting and valuable to use robots in language learning and teaching, Furthermore, using robots is not restricted to engineering and science students. The use of robotic systems by nontechnical and non-engineering teachers has nominated as a "robotics revolution" (Hendler, 2000). There have been many studies to use robots in mathematics and science, but few investigations have explored useful and potential advantages of using them for language learning and teaching and to develop an optimal design and model of language teaching robots. Robots can be programmed to "hear", "speak" to enhance learning( Shih et al., 2007) and learners engage and enjoy more(Xie et al.,2008).

One of the ultimate objectives of computer- assisted language learning (CALL) is to supply learners with a good context to acquire communicative competence in the second language. A number of important factors have been proposed for improvement of students' productive conversational skills: 1 . Comprehensible input 2.corrective feedback 3. Comprehensible output 4. Motivation and attitude. Through corrective feedback, students can evaluate the linguistic well-formedness and comprehensibility of their utterances to understand what they know and what they do not know. The output hypothesis claims that output or production causes the learner to move from "semantic processing" to more "syntactic processing". It is very paramount to identify learners' motivation and attitude that helps in successful acquisition of a foreign language. Computer -based learning can increase the students' motivation because it has both an advantage over human- based learning and it is more relaxing atmosphere.

\subsection{Theoretical Rationale behind the Use of RALL}

The total physical response approach (TPR) (Asher, 1982), puts emphasis on learning through actions and movements. In this approach, a teacher is in the role of commander, and the learners are the actors. But learners are reluctant to be ordered and dominated by the teacher or other students. Fortunately, robots can be actors and students can command. (Wu, Chang, Liu, Chen, 2006).

Moreover, in the natural approach, the stress of the context and communication disable leaners in learning process. Krashen and Terrel (1983) suggested affective filter hypothesis, proposed that a relaxed situation and mode, self- confidence, and strong motivation were very rewarding for language acquisition. Pictures, videos, and puppets could aid learners in communication. But such tools can interact and communicate with students directly. Later, the task-based language teaching (TBLT) and communicative approach have been very famous for teaching English as a foreign language in Asian countries(Kan, 2004;Nunan, 2003).

Littlewood (2003) expresses concerns about using TBLT including: classroom management (Morris et al., 1996), minimal demands on language requirements and competence (Carless; 2004) and avoidance of using and speaking English. (Li, 2003).However, using robots in foreign learning activities might solve the management problem by being a stimulator or manager. They may also diminish the English avoidance strategy. The robots could be regarded as foreigners, so that students would have to talk in English to have a good communication with them (Kada\& Ishiguro, 2005).

Weinberg and $\mathrm{Yu}$ (2003) expounded two important factors that robots will support educational understandings. First, they are the concrete embodiment of computations and provide excellent experiences for the learner. Second, the plug and feel of the new robot platforms which motivate the learners to interact with them.

\subsection{Current Instructional Media for Learning and Teaching a First, Second, And Foreign Language}

Common educational tools have been utilized in kindergarten and elementary language classes (Heinich et al., 2002). These ordinary tools are: visual, audio, computer, internet, video and different mobile devices (Chinnery, 2006).Mayer and Mereno (1998) and Mayer (2001) indicate that multimedia were extraordinarily better than mono-media. Educational tools usually support these characteristics: recall prerequisites, present new content, gain attention, present the lesson objectives, giving examples, visual elaboration, enhance retention and transfer, evaluate performances, provide feedback and elicit student answer(Heinich, Smaldino, Russell\& Molenda, 2004). Moreover the use of multimedia for second and foreign language teaching and learning has increased substantially over the two decades.

Mobile technology, with devices such as Android phones, iPhones, and iPod's, is dominating our educational context towards concentrating on mobile learning or m-learning. In the future one of the newest technologies will be robotics. Since the invention of various media, from the one-way mass media TV, to different kinds of computers with improved interactivity to computer- aided instruction (CAI) The instructors have used them in their education. Furthermore, the invention of internet and World Wide Web has changed Computer-aided instruction (CIA) into internet- based instruction.

Media can assist language learning in several ways: 1.Facilitating communicate 2.Reducing anxiety. 3. Providing oral conversation 4.Developing writing- thinking association5. Encouraging cooperative and collaborative 
learning. 6. Enhancing egalitarian class status 7. Increasing learners' motivation 8. Sharing cross- cultural consciousness 9. Developing writing skills 10.Performimg the role of the native speaker in the language classes.

\subsection{Mobile Assisted Language Learning (Mall) and Computer-Assisted Language Learning (Call)}

Direct interaction with a native speaker has been confirmed to be the most influential way of learning a foreign language. In foreign language context, presence of a native speaker is difficult. Using a computer or mobilebased application has its own limitation. The most beneficial and the fast technology to fulfill the place of a native speaker is a robot. Robots do not seek to supplant teachers, but rather to assist and reinforce the material by repetition. An intelligent RALL system with voice recognition and vision ability can supply an environment for communicative discussion.

Stockwell (2007) summarized and analyzed the literature in computer- assisted language learning (CALL) and using different devices to enhance learners' abilities in language (reading, writing, speaking, listening, pronunciation, vocabulary, grammar). With enhancement of computer and mobile devices, Mobile Assisted language learning (MALL) and Computer Assisted Language Learning(CALL) have been the center of public interest for second and foreign language educational theories for nearly a decade.

Robots not only have the attributes of CALL/MALL, but also are able for independent movements, voice/visual recognition and environmental interactions. Robots are also capable of non-verbal communication, such as gestures, facial expressions and actions. With the features embodied in many robots like adaptability, sensing, repeatability, intelligence, mobility and human appearance, the RALL system can create a useful collaboration with student to improve their speaking and listening abilities and to provoke the learners' interest, collaboration and motivation in problem solving abilities and specific tasks.

Robots are different from personal computers, because they have a friendly human appearance, a name, a personality, a birth story and they are able to have social collaborations. In addition, robots have computer displays on their bodies that provide mobile services just like computers and other mobile devices. RALL systems have the values of the traditional collaboration, the face to face, physical interaction with native speakers. Furthermore, it also shares instructional material over a TV screen, or a display device.

Nowadays, in most Asian countries, many instructional methods are used to teach a foreign language. These methods and robots provide collaboration with native speakers, diagnosing pronunciation, video conferencing with native speakers and native speaker tutoring. However, because of limitations in image recognition, most devices are based on voice- based messages. But video conferencing with native speakers can be influential. The benefits of one- to- one native speaker tutoring and individualized interaction are tremendous, but it is costly forstudents and no help is available in the students' mother tongue.

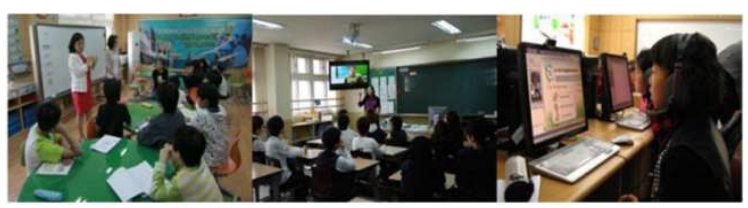

Figure 1. A traditional collaborative class, a video conferencing class, and a one-on-one conference in Korea. (Language Learning \& Technology http. //lt.msu.edu/issues/october2012/emerging.pdf)

\subsection{Robot- Aided Learning(R- Learning)}

Robot- aided learning ( $r$ - learning) services can be described as interactive and instructional activities which can be interacted and performed between robots and learners in both the virtual and real worlds. R- Learning has seven advantages: responsiveness of teaching and learning activities, greater frequency of physical and virtual space, reciprocal authority to start learning, the anthromorphism of media, convenient communication for teachers and parents, providing fantasy, providing physical activities.

According to the Korean Times(Thursday, April 1st, 2010, Ryan Schuster), "During the second decade of third millennium robots will replace English speaking teacher in Korea. By 2018, 25,000 English teachers on the peninsula will be out of work." Robots were extensively used for automatic manufacturing and tool making. With this robot revolution, robots are more widespread. They take the role of a service robot at home, doing menial tasks. However, their use in instruction has great potentiality, especially in language teaching. And also today robots are used as vacuum cleaners, tour guides, pets, autonomous vehicles, lawn mowers and even teachers. They can do everything for you. For example: cooking, working, getting you a drink.

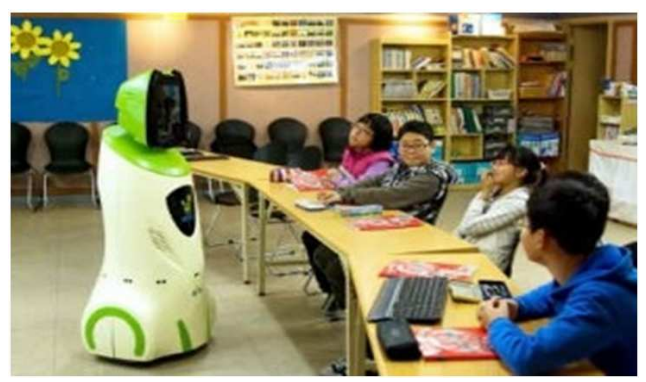

Figure 2. A robot teacher teaching students.

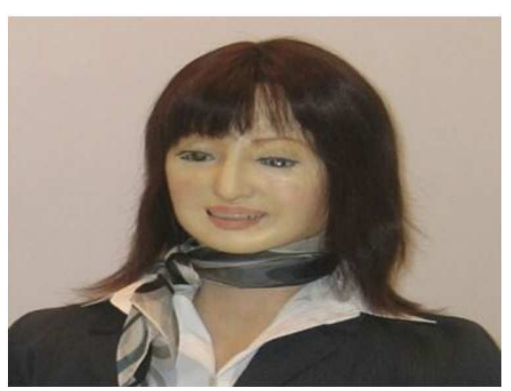

Figure 3. Saya (a robot teacher in Korea). 
The concept of robot was predicted in many novels and movies before this interesting technology was accessible. Although modern robots are designed and developed for special objectives, they will be mass- produced with lesser costs in the future.

\subsection{Characteristics of Robots}

There are ten characteristics of robots that might help to support language learning instruction:

\subsubsection{Repeatability}

Robots regurgitate educational activities many times without complaining. This feature not only assists teachers, but also helps children to practice orally. A school teacher uses the same teaching activity in different classes in many terms. Repetition has many advantages for learners, comprehension and familiarity with the spirit of a language.

\subsubsection{Flexibility}

It permits instructors to design and adjust proper robotsupported educational activities for instructional needs. Learners are not limited to specified instructional materials developed by the manufacturer. This attribute may engage children to take part in language course development and minimize the distance between students and teachers. In addition, they are adjusted to the specific level of the students.

\subsubsection{Digitization}

As robots are digital, they can help to preserve the digital data. A robot- supported language education data base can record instructors' experiences and students' portfolios. Robots can communicate through Bluetooth or $\mathrm{Wi}-\mathrm{Fi}$ with computers.

\subsubsection{Humanoid Appearance}

Robots are more engaging and provoke fantasy and curiosity among children and increase learners' motivation to practice language skills joyfully in a more real- life way. They engage, motivate learners and help them to cut down their anxiety level.

\subsubsection{Body Movement/ Motion}

Robots accompanied with different gestures not only arouse motivation but also lead and help children to use suitable gestures while talking. It can assist learners to recognize unknown words used by the robot. Specific comical or exaggerated movements cannot perform by the classroom teacher but they can be done by the robots.

\subsubsection{Interaction}

Robot ability to interact with children effectively is one of the basic functions to become teaching assistant. Practicing different dialogues is important in language learning classes. Moreover, by voice recognition features, robots can give suitable responses (House, \&Balms, 2009)

\subsubsection{Anthropomorphism}

In direct opposite to other educational media, learners behave with robots as real speakers and participants. Hence, learners are not concerned that they will be humiliated or scoffed at for strange pronunciation or mistake.

\subsubsection{Sensing Capability, Intelligence and Automatic Speech Recognition}

It enables robots to sense environment by light sensors (eyes), chemical sensors (nose), touch and pressure sensors (hands), taste sensors (tongue) and even hearing sensors (ears). Robots are equipped with artificial intelligence that helps them to communicate with human and computers .Speech recognition is done by a speaker independent real- time speech recognizer.

\subsubsection{Language Understanding and Dialogue Management}

Since language students often make different errors, a system should understand their utterances in spite of these hurdles to anticipate error kinds. This can be done by taking not only the utterance but also the dialogue environment into consideration. The dialogue manager produces system responses according to the learners' intent and produces corrective feedback.

\subsubsection{Emotional Expression}

The learners' understanding of robots' emotions is very important in human- robot interaction. Robots can represent different emotions: for example, hope, joy, fear, dislike, neutrality, pride, sadness, shame, surprise, distress, embarrassment. They can also make different gestures according to the meaning of a verbal response: yawning, sulking, winking, and cheering.

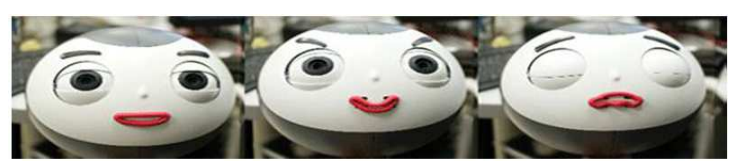

Figure 4. Facial expressions for some emotions (Lee, 2010).

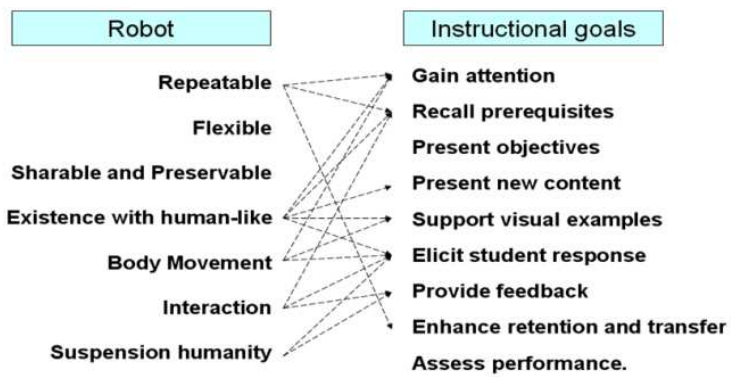

Figure 5. The relationship between robot attributes and instructional tool goals.

\subsection{Different Scenarios (Modes) and Activities to Apply Robots in Language Classes}

The following robots modes and activities can be used as classroom activities and interactions. 


\subsubsection{Story Telling}

It can be stimulating activity for language learners (Gravies, 1990).Robots can tell the stories in female or male voices that are ideal for excellent roleplaying. It can imitate different voices and perform comic actions.

\subsubsection{Oral Reading}

Brown (2000) and Castagno (2006) pointed out that the learners practice pronunciation and verbal capacity by memorizing and reading continuously, they will speak more quickly and fluently. In oral reading mode, the robot leads students to recite sentences and words. It can change the speed of speaking and male and female voices let students to exercise speaking. While the robots led the reading phase, the teacher could monitor students' pronunciation and intonations.

\subsubsection{Cheerleader Mode}

If the learners are encouraged, they engage in learning activities fully and enthusiastically all the time, they have great learning experiences according to flow theory (Csikszentmihalyi, 1990). The robot can help the teacher and encourage learners to take part in the games. When a learner or a team wins the game, the robot will shout and dance for enjoyment.

\subsubsection{Action-Command Mode}

According to Asher (1982), learners acquire comprehension capability by responding to their parents' commands before they speak. In this mode, the robot commands students to perform a specific task. The students can ask the robot to perform the requested actions. The robot obeys the learners' commands automatically.

\subsubsection{Question and Answer $(Q \& A)$}

CLT (Higgs \& Clifford, 1982; Finocchiaro \& Brumfit, 1983 ) is used to develop the students' communicative competence and the learners use language to talk, comment and communicate their feelings and emotions. Question and answer mode is used to meet these needs.

\subsection{Identification of Roles and Activities of Assisted Robots}

\subsubsection{Learning Materials}

Students can design and develop robots to increase their motivations and improve skills in math, programming, science, and problem- solving by collectable and programmable teaching tools. In language learning, students can design robots to have learning materials. They can create and express their own stories by using mobile robots.

\subsubsection{Learning Companion/ Pets}

Human -like robots can be considered as learning fiend or companions. Kanda et al. (2004) designed a robot named Robovie that was behaving like an English language peer tutor for Japanese students. Kanda and Ishiguro (2005), in their study showed that children's recall of new vocabulary enhanced and they found a positive frequency of interaction with robots and learning achievement.

\subsubsection{Teaching Assistant}

Robot can be used as instructing assistants to accompany and encourage learners to engage and learn more. The basic aim of a teaching assistant is to assist teachers to present materials and to manage the students. As an example, robot Irobi was used as an assistant in a class. It used a monitor in the belly to display information. (Jeoghye et al., 2005)

\subsubsection{Other Robots' Roles and Activities}

Robovie robot in Kanda provides the learners with voiced - based English conversation and non-verbal interaction like playing rock-paper-scissors. Papero robot (Osada, (2005) performed the following activities: roll-call of the attendees, conversation, reactions to touching different points, quizzes, making stories, and roleplaying.

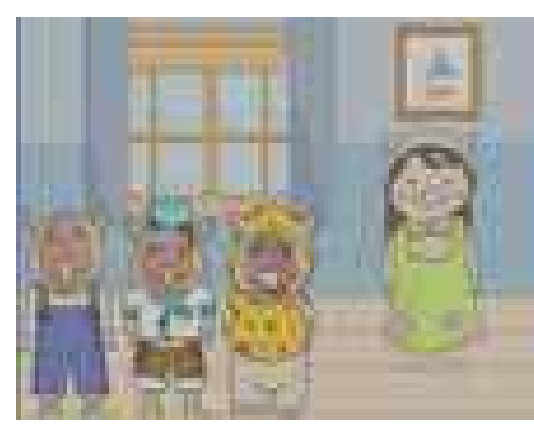

Figure 6.Augmented Reality Role Playing.

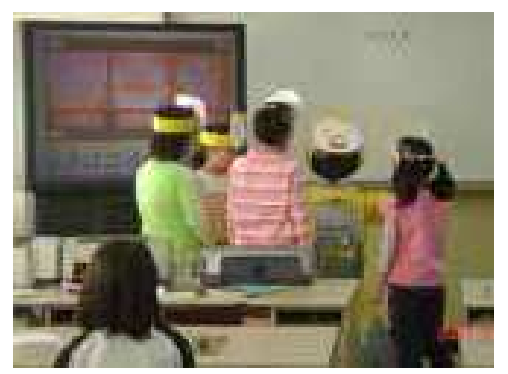

Figure 7. Conversation

Peer -tutor is the dominant role of a robot (Kanda et al., 2004) followed by robots as teaching assistant (Han \& Kim, 2006). Some robots embraced a wide range of users, for example preschool children, adults and elders (Osada, 2005), younger partner, an instructor or an assistant and an elder partner. Taylor (1980) declared that computers have paramount roles as instructional tutors, tools and tutees.

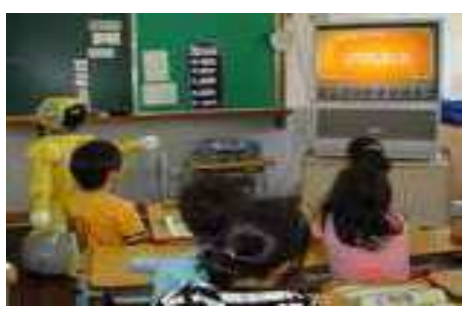

Figure 8. Calling the Roll. 


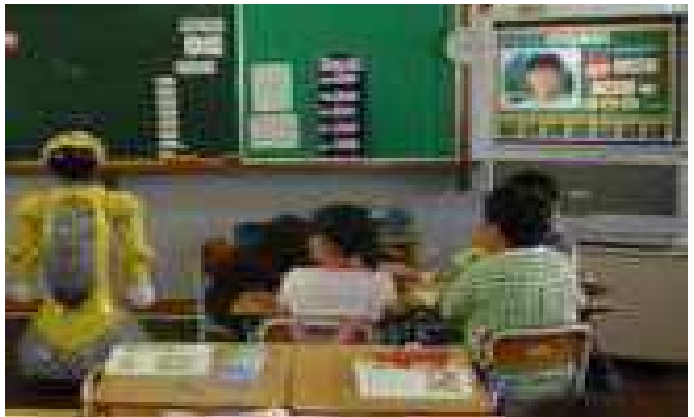

Figure 9. Getting Attention.

Tiro's services contained children's photo and names. Its other services also are divided into two kinds: 1. Class management, such as calling the roll, getting attention, selecting presenter and acting as a timer.2. Learning materials which are transmitted to $\mathrm{TV}$, such as lesson objectives, storytelling, conversation scripts, dancing, English chants, role playing, cheering up and praising, providing quiz games.

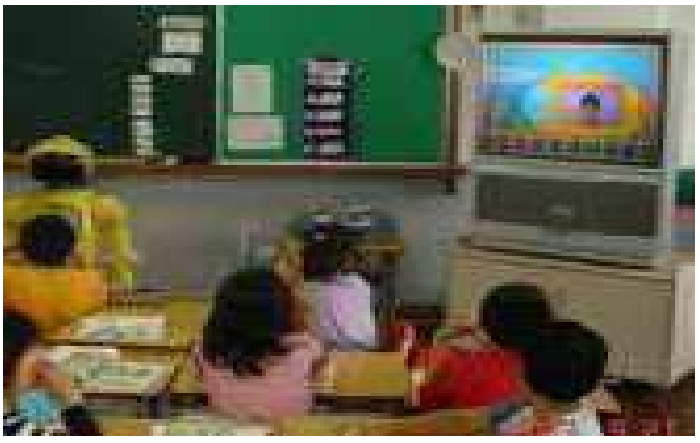

Figure 10. Selecting Children to Present.

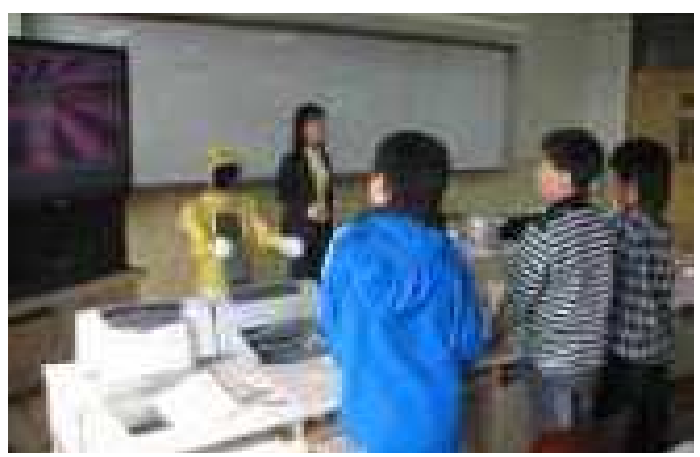

Figure 11. English Chant and Dance.

They also do activities like supporting English learning, playing music, reading books, guiding daily activities( e.g., eating, cleaning), collecting and compilingchildren's academic portfolios and photosand then transmitting them to learners' parents via e-mail or mobile phone, singing a lullaby, teaching general eating etiquette such as washinghands.

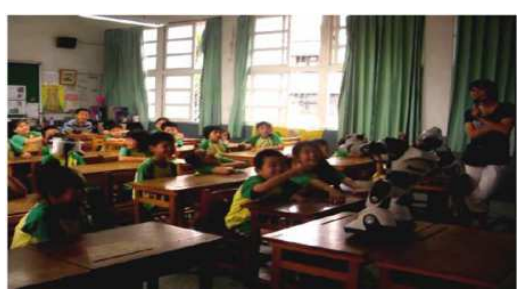

Figure 12. Students giving the robot commands.

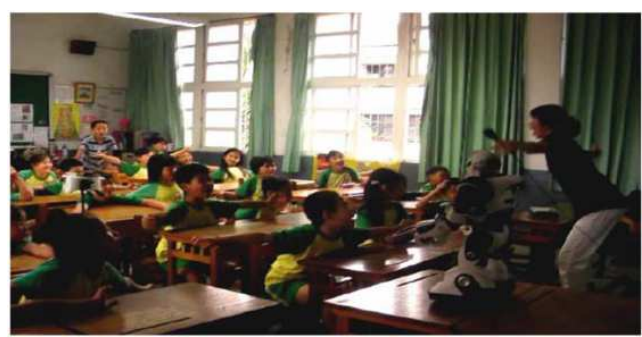

Figure 13. Teacher telling a story with a robot.

\subsection{Different Kinds of Educational Service Robots and Related Works on RALL}

Designing and development of RALL began approximately around 2004, conspicuously in Japan, Taiwan, and Korea, where English language is taught as a foreign language. The design of robot services are made up of five stages: the design of voice, vision, nonverbal, emotion, and object recognition. There are two kinds of instructional robots: hands- on and educational service robots. Hands-on robots are used to enhance creativity and promote interest in instruction that stands for science, technology, engineering, and mathematics. Educational service robots which are intelligent can create collaborative relationships with children, make learning more enjoyable and increase students' enthusiasm by lowering their emotional barrier i.e. affective filter (Han, 2010).

Educational service robots are divided into three types: the tele-operated, autonomous, and transformed types which are categorized according to the location of their artificial intelligence.1. Tele- operated type: it supplies the tele-presence of instructional services through a remote controller that the instructor uses. 2. Autonomous type: it has its own created artificial intelligence.3. Transformed type: it has both autonomous andtele-operation control and can switch between these two operations.
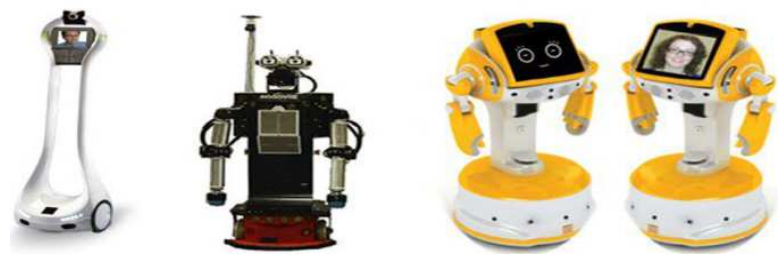

Figure 14. VGO is tele- operated (left), ROBOVIE is autonomous (center) and ROBOSEM is transformed (right). (Language Learning \& Technology http. //llt.msu.edu/issues/october2012/emerging.pdf) 
First educational robots applications were in Canada, Taiwan, South Korea, Japan and United States. For example, there are: Japan's Robovie as a peer tutor for teaching English at elementary school, Paperno(2004)for child- care, Keepon(2007) as an collaboration inducer for children suffering from autism, Saya(2010)for utilization in Japanese preschools; Iroobi (2005) as a teaching assistant preschool, Irobioiq(2008) for use in primary school English teaching, Robosem(2011) as an English teaching assistant; Robosapien(2006) as Taiwan's elementary teaching assistant; Rubi was usedin the United States preschool peer tutor and Vgo(2011) for young patients; Nima (2013)used in Iran' junior high schools as a teacher assistant.

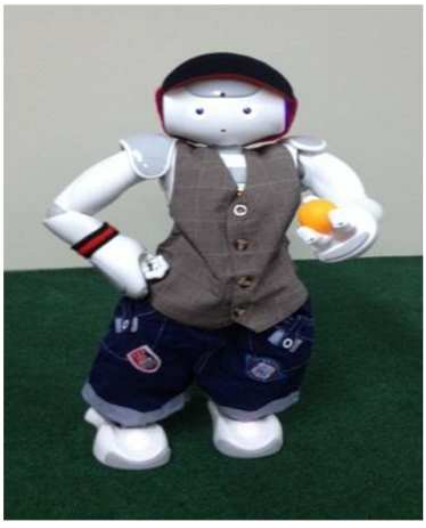

Figure 15. the NAO (NIMA) Robot.

Some interesting findings about using robots have been reported. Movellan et al., (2005) reported that English vocabulary learning was better when they used Rubi. Han and Kim (2009) introduced robot Tiro in elementary school classes. The results showed that it enhanced the relationship between the robot and children in English classroom. Tiro cheering and praising, face to face conversation were the most services.

Han (2010) found that in the United States and Japan, robots have a peer tutor, but in Korea, they are given the role of a friend or a teacher assistant. Park et al. (2011) designed and developed classrooms material with Robosem that showed meaningful results. Alemi et al.(2013) working with Nima, a customized robot in Iran among female first grade junior high school students to understand RALL impact on students' vocabulary development. Lee et al. (2011) investigated the cognitive effects of RALL approach on the students' oral skills. The results indicated that the students' speaking skills improved with a large effect size.

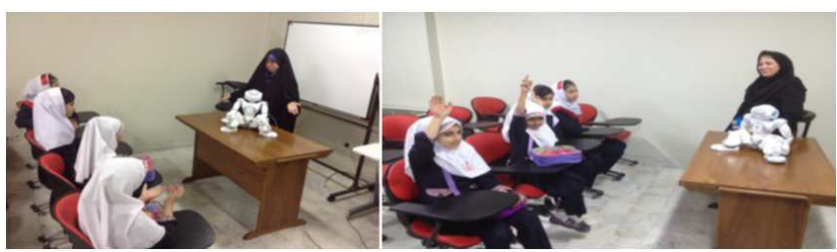

Figure 16. Nima as a teacher assistant in Iran's robotic project in junior high school.
Japan conducted research on learner motivation with Robovie (Kanda, Hirona, Eaton\& Ishiguro, 2004). Korean developer (Yujin, 2004) announced a home robot Irobi that performed services like reading English, English chanting and photo books. Through a Delphi survey of school teachers, Han and Kim (2005) found that RAL instruction is the most suitable for subjects like English, music and Korean. You et al. (2006) used Robosapien to an English classroom with five educational models. Hyun, Kim, Jang\& Park (2008) indicate that a robot is more effective than computers in preschoollers' vocabulary expansion, story building, word recoginition in Korean language reading activities.

Mishra and Koehler $\left(200^{\wedge} 0\right.$ searched about teachers' knowledge, which was based on the idea of Pedagogical Content Knowledge (PCK) that was proposed by Shulman (1987). Later, they extended PCK to TPCK (Technological Pedagogical Content Knowledge) that considers the necessary relation between teachers' subject knowledge, technology and pedagogy.

Kanda et al.(20070 indicated tat robots may need to use leaner's native language to have a good relationship .Robovie serves many interactive behaviors such as hugging, play rock-paper-scissors, exercising, shaking hands, kissing, greeting, singing, and pointing to an object. Rubi, a fun- looking robot tutor taught the children numbers, vocabulary, colors and other basic concepts and sang popular songs. Robosapien robot (You et al., 2006) had five models of services; story telling model; Question and Answer (Q\&A) model; let's act model; pronunciation leading model; and cheerleader model.

\subsection{Challenges to RALL}

Many countries which teach English as a foreign language have tried to apply RALL and begun its commercialization. In Korea, over 1500 robots are used for playing activities and attitude training, and over 30 English instructional robots are utilized in elementary after school activities. But there are some challenges to address and tackle with.

First, research should be done on its system framework such as its hardware, applications and visual contents. Both educationalists and educational service robot developers need to do collaborative research on designing this system framework.

Secondly, more theoretical study on the RALL instruction model is desirable. More specific teaching and learning model, more researches on human- robot interaction (HRI) model are needed under language learning experts' perspective.

Third, more field studies and experiments on robots' instructional effectiveness are needed to compare RALL to the traditional educational methods and to improve more specific native speaker collaboration model.

Fourth, teacher training research is necessary. We should take into account what teachers need to implement RALL 
in their classes, because they are the ones that will use and install RALL in their classes.

Fifth, researches on different technological and ethical and moral issues and violations are essential. For instance, the exposure to outsiders through tele- conferencing ; learners ' trusting a robot over their teacher; sharing data on class activities and misuses by a tele- presence system by a remote teacher that unapproved visual and audiorecordings that may be distributed; and possible obsession with robots.

Sixth, management problems like network or robot hardware breakdown are needed to consider in advance. Recognition ability and knowledge framework of a teaching robot are still restricted. The cost benefit and uniqueness of robots have been very controversial in comparison with computer services.

These diverse studies and discussions show that robots can be used to support instruction and different educational robot roles and advantages have been suggested. Although many researches have emphasized using robots to assist students and learners in mathematics and science, few studies have tried to use robots in language teaching .Despite the fact that Kanda et al. have been pioneers to use robots in language classroom, it is essential to use robots more comprehensively to enhance language learning and teaching. The aim of this study is to search this new line of research to discover humanoid robots for teaching a foreign language in a junior high school. As computer revolutionized the learning environments, studies are needed to know how robots will cause great changes in language instruction. Preparation of different approaches and methods for RALL from the view of language learning and pedagogy will be of paramount importance.

\section{References}

[1] A. Meghdari, M. Alemi, M. Ghaazisaidi, A. R. Taheri, A. Karimian, and M. Z. Vakili, Applying Robot Teaching Assistant in EFL Classes at Iranian Middle-Schools. In Proceedings of the 2013 International Conference on Education and Modern Educational Technologies (EMET2013), Venice, Italy September 28- 30, 2013.

[2] B. House, J. Malkin, and J.A. Bilmes, The VoiceBot: A voice controlled robot arm. In Proceedings of CHI 2009. New York: ACM Press. 2009.

[3] C. C. Wu, C. W. Chang, B. J. Liu, and G. D. Chen, Improving vocabulary acquisition by designing storytelling robot. In Proceedings of 8th IEEE International Conference on Advanced Learning Technologies, Washington, DC: IEEE Computer Society, 2008, pp. 498-500.

[4] C. F. Shih, C. W. Chang, and G. D. Chen, Robot as a storytelling partner in the English classroom: Preliminary discussion. In Proceedings of the Seventh International Conference on Advanced Learning Technologies, Washington, DC: IEEE Computer Society, 2007, pp. 678682
[5] C. Y. Li, "A study of in-service teachers' beliefs, difficulties and problems in current teacher development programs," HKBU Papers in Applied Language Studies, Vol. 7, pp. 64$85,2003$.

[6] D. Carless, Issues in teachers' reinterpretation of a taskbased innovation in primary schools. TESOLQuarterlyVol.38, No.4, 2004, pp.639-662.

[7] D. Nunan, The impact of English as a global language on educational policies and practices in the Asia-Pacific region, TESOL Quarterly, Vol. 37,No. 4, 2003,pp. 589-613.

[8] E. Garvie, Story as vehicle: Teaching English to young children. Clevedon, Avon, UK, 1990

[9] E. Hyun, S. Kim, S. Jang, and S. Park, "Comparative study of effects of language education program using intelligence robot and multimedia on linguistic ability of young children." Proceedings of the 14th IEEE International Workshop on Robot and Human Interactive Communication, RO-MAN. 2008, Piscataway, NJ: IEEE, 2008.

[10] G. Stockwell, A review of technology choice for teaching language skills and areas in the CALL literature. European Association for Computer-Assisted Language Learning (ReCALL), Vol. 19, No. 2, 2007, pp. 105-120.

[11] H. Jeonghye, K. Dongho, L. Kyung Seon, P Sung Ju, and S. Kyung Chul, A teaching assistant robot in elementary schools. In Proceedings of the 2nd International Conference on Ubiquitous Robots and Ambient Intelligence. Seoul, South Korea, 2005.

[12] H. Ryu, S. S. Kwak, and M. Kim, A study on external form design factors for robots as elementary school teaching assistants. In Robot and Human interactive Communication, 2007. RO-MAN 2007. The $16^{\text {th }}$ IEEE International.

[13] H. W. Kam, English language teaching in East Asia Today: An overview. Asia Pacific Journal of Education. Vol.22, No.2, 2002, pp 1-22.

[14] J. Han, Robot-aided learning and r-learning services. In D. Chugo Ed., Human-Robot Interaction. Retrieved from: http://sciyo.com/articles/show/title/robot-aided-learningand-r-learning-services, 2010.

[15] J. Hendler, Robots for the Rest of Us: Designing Systems Out of the Box. Robots for Kids-Exploring New Your,2000

[16] J. J. Asher, Learning another language through actions: The complete teacher's guidebook, 2nd ed., Los Gatos, CA: Sky Oaks Productions. 1982.

[17] J. M. Han, S. Park, and S. Kim, The Educational Use of Home Robots for Children. In Proceedings of the 14th IEEE International Workshop on Robot and Human Interactive Communication (ROMAN, 2005), 378-383. Piscataway, NJ: IEEE, 2005.

[18] J. R. Movellan, F. Tanaka, B. Fortenberry, and K. Aisaka, The RUBI/QRIO Project: Origins, principles, and first steps. In Proceedings of The 4nd International Conference on Development and Learning, 2005, pp. 80-86, Retrievedfrom http://doi.ieeecomputersociety.org/10.1109/DEVLRN.2005. 1490948.

[19] L. S. Shulman, Knowledge and teaching: foundations of the new reform, Havard Educational Review, Vol. 57, No. 1, 1987, pp. $1-22$ 
[20] L. Xie, A. N. Antle, and N. Motamedi, Are tangibles more fun? Comparing children's enjoyment and engagement using physical, graphical and tangible user interfaces. In TEI '08: Proceedings of the2nd International Conference on Tangible and Embedded Interaction, New York: ACM, 2008 pp. 191-198.

[21] M. F, Csikszentmihalyi, The psychology of optimal experience. New York: Harper and Row. 1990

[22] P. J. T. F. Morris, R. Au. M. L. Adamson, K. K. Chan, W. Y. Ko. P. Y. Chan, and P. H. Wong, Target-oriented curriculum evaluation project: Interim report. Hong Kong: INSTEP, Faculty of Education, The University of Hong Kong, 1996.

[23] R. Heinich, M. Molenda, J. D. Russell, and S. E. Smaldino, Instructional media and technologies forlearning, $7^{\text {th }}$ ed., Upper Saddle River, NJ: Merrill Prentice Hall, 2002.

[24] R. E. Mayer, and R. Moreno, A cognitive theory of multimedia learning: implications for design principles. In Proceedings of Annual meeting of the ACM SIGCHI Conference on Human Factors in Computing Systems. New York: ACM, 1998.

[25] R. E. Mayer, Multimedia learning, New York: Cambridge University Press, 2001

[26] R. P. Taylor, The computer in the school: Tutor, tool, tutee, Ed., New York: Teacher's College Press, 1980

[27] S. C. Yang, and Y. J. Chen, Technology-enhanced language learning: A case study. Computers in Human Behavior, Vol. 23, 2007, pp. 860-879.

[28] S. E. Smaldino, J. D. Russell, R. Heinich, and M. Molenda, Instructional media, and technologies for learning, 8th ed.,
Upper Saddle River, NJ: Prentice Hall Stockwell, G, 2007. A review of technology choice for teaching language skills and areas in the CALL literature. European Association for Computer-Assisted Language Learning (Re CALL), Vol. 19, No. 2, pp. 105-120.

[29] S. Krashen, and T. Terrell, The natural approach: Language acquisition in the classroom. Oxford Pergamon, 1983.

[30] S. Lee, H. Noh, J. Lee, K. Lee, and G. G. Lee, "Cognitive effects of robot-assisted language learning on oral skills," In INTERSPEECH 2010 Satellite Workshop on Second Language Studies: Acquisition, Learning, Education and Technology, 2010.

[31] S. Papert, The children's machine: Rethinking school in the age of the computer. Basic Books. New York, 1993.

[32] T. Kanda, and H. Ishiguro, "Communication robots for elementary schools," In Proceedings of the Symposium on Robot Companions: Hard Problems and Open Challenges in Robot-Human Interaction, (pp. 54-63). Brighton, 2005

[33] T. Kanda, T. Hirano, D. Eaton, and H. Ishiguro,. Interactive robots as social partners and peer tutors for children: A field trial. Journal of Human Computer Interaction, Vol.19, No.1-2, 2004, pp. 61-84.

[34] W. Littlewood. Task-based language teaching: Theory and practice, ACELT Journal, Vol.7, No.1, 2003, pp. 3-13.

[35] Z. You, C. Shen, C. Chang, B. Liuand, and G. Chen, A robot as a teaching assistant in an English class. In Proceedings of the 6th IEEE International Conference on Advanced Learning. Technologies, New York, NY: IEEE, 2006, pp. 87-91. 